Revista IBERC

v. 2, n. 3, p. $01-15$, set.-dez./2019

www.responsabilidadecivil.org/revista-iberc

\title{
RESPONSABILIDADE CIVIL E TERCEIRIZAÇÃO: UM NECESSÁRIO DIÁLOGO ENTRE DIREITO CIVIL E DIREITO DO TRABALHO
}

\author{
CIVIL LIABILITY AND OUTSOURCING: A NECESSARY DIALOGUE BETWEEN CIVIL LAW AND \\ LABOR LAW
}

Thiago Rodovalho ${ }^{\mathrm{i}}$

RESUMO: Este artigo visa a analisar a exegese do Código Civil art. 932 inc. III na terceirização, é dizer, quando e como é possível a extensão da responsabilidade civil objetiva e solidária prevista no aludido artigo ao contrato de prestação de serviços por terceirizada. Nesse contexto, defendemos a necessidade de que haja "relação de subordinação" entre o agente causador do dano e o terceiro a quem se pretende imputar a aludida responsabilização. Na ausência desse vínculo de subordinação, essa extensão não é juridicamente admissível.

Palavras-chave: Responsabilidade civil objetiva. Responsabilidade civil solidária. Terceirização. Contrato de prestação de serviços por terceirizada. Relação de subordinação.

\begin{abstract}
This article aims to analyze the exegesis of the Civil Code art. 932 inc. III in outsourcing, that is to say, when and how it is possible to extend the objective and solidary liability provided for in the aforementioned article to the contract for the provision of services by third party. In this context, we defend the need for a 'subordination relationship' between the agent causing the damage and the third party to whom the aforementioned liability is imputed. In the absence of such a tying link, such an extension is not legally admissible.
\end{abstract}

Keywords: Objective civil liability. Solidary civil liability. Outsourcing. Contract for the provision of services by third party. Subordination relationship.

SUMÁRIO: 1. À guisa de introdução: a importância da noção de sistema no Direito e do necessário diálogo entre Direito Civil e Direito do Trabalho. 2. Estado Democrático de Direito e o exercício do Poder Judiciário. Procedimento e fundamentação como pressupostos de legitimação à atuação democrática do Poder Judiciário. 3. CC art. 932 inciso III. Consagração da responsabilidade civil por fato de outrem. Norma que alude a empregador ou comitente. Hermenêutica jurídica para saber quando e como pode ser estendido ao contrato de prestação de serviços por terceirizada. 4. Conclusão. Referências.

\footnotetext{
Professor Titular da PUC-Campinas (Graduação e Mestrado). Membro do Corpo Docente Permanente do Programa de Pós-Graduação Stricto Sensu em Direito (PPGD). Doutor e Mestre em Direito Civil pela Pontifícia Universidade Católica de São Paulo - PUC/SP, com estágio pós-doutoral no Max-Planck-Institut für ausländisches und internationales Privatrecht.
} 


\section{1. À GUISA DE INTRODUÇÃO: A IMPORTÂNCIA DA NOÇÃO DE SISTEMA NO DIREITO E DO NECESSÁRIO DIÁLOGO ENTRE DIREITO CIVIL E DIREITO DO TRABALHO}

O presente tema traz uma interessante oportunidade de debater a imanente intersecção que há entre o Direito Civil e o Direito do Trabalho, tema que tem sido relegado - em nosso sentir equivocadamente -, a um segundo plano.

Não foi sempre assim. Já tivemos, em tempos não tão distantes, uma relação muito profícua entre ambos os ramos do direito. Basta lembrarmos, p. ex., de Orlando Gomes, um dos maiores civilistas que esse país já conheceu, e que também era profundo cultor do Direito do Trabalho, tendo transitado com invulgar desenvoltura nas duas áreas (Livre-Docente, foi regente da Cátedra de Direito Civil, em 1935, na Faculdade da Bahia, atual UFBA, e em 1936, passou a cumulá-la com a Cátedra de Direito do Trabalho, tendo sido seu primeiro regente), ${ }^{1}$ tendo, inclusive, publicado obras e artigos em ambas. ${ }^{2}$

Nesse sentido, em passagem pelo país em 2017, o professor português Pedro Romano Martinez, atual diretor da Faculdade de Direito da Universidade de Lisboa, e, a exemplo Orlando Gomes, igualmente com docência e escritos em ambas as áreas, Civil e Trabalho, tendo sido, inclusive, o coordenado da equipe de juristas que elaborou o novo Código do Trabalho de Portugal (Lei 99, de 27 de agosto de 2003), pronunciou-se a esse respeito: "O Direito do Trabalho não se beneficia de ser um ramo separado do Direito Civil.
Isso porque a especialização nessa área acaba dificultando a conexão com os
princípios fundamentais e com outras áreas jurídicas
[...]
Essa afirmação segue a linha do que tenho afirmado em relação ao Direito do
Trabalho e, em razão disso, sou normalmente mal compreendido pelos laboralistas:
a ideia de que o Direito do Trabalho tem de viver um mundo à parte, alheio ao
Direito Civil, não é nada benéfica para o Direito do Trabalho. A lógica de se manter
uma base comum de caráter geral parece-me ser preferível para a solução dos
casos. A criação de regimes traz geralmente consigo jurisdiçães diferenciadas e,
depois, como mundos distintos, muitas vezes não comunicáveis entre si.

$[\ldots]$

RDCC - No Brasil, é comum dizer que o Direito do Trabalho não integra mais o Direito Privado e que se teria constituído em um ramo híbrido, integrando o Direito Público e o Direito Privado, ou mesmo se colocando como um Direito sui generis. $O$ senhor concorda que o Direito do Trabalho deixou de integrar 0 Direito Civil?

Pedro Romano Martinez - Tenho defendido que não. Mantenho a ideia de que é Direito Privado. Evidentemente tem especificidades, nomeadamente resultantes da intervenção do Estado, em vários níveis, no âmbito de proteção do trabalhador. Mas isso, na minha perspectiva, não o desvirtua.

RDCC - O senhor considera que a autonomia judiciária do Direito do Trabalho é um fator benéfico para o trabalhador ou seria um fator que aumenta a

\footnotetext{
${ }^{1}$ Cfr. GOMES, Orlando. Curriculum Vitae. In: Faculdade de Direito da Universidade Federal da Bahia. Estudos jurídicos em homenagem ao Professor Orlando Gomes, Rio de Janeiro: Forense, 1979, p. IX/XII.

2 A título de exemplo, no Direito do Trabalho: Convenção do Trabalho, Bahia, 1936; Direito do trabalho estudos, 3. ed., São Paulo: LTr, 1979; Introdução ao direito do trabalho, Rio de Janeiro: Forense, 1944; O salário no direito brasileiro, Rio de Janeiro: Konfino, 1947; e Curso de direito do trabalho (em colaboração com Elson Gottschalk), Rio de Janeiro: Forense, 1978. No Direito Civil: Introdução ao direito civil, Rio de Janeiro: Forense, 1957; Direitos reais, Rio de Janeiro: Forense, 1958; Contratos, Rio de Janeiro: Forense, 1969; Obrigações, Rio de Janeiro: Forense, 1960; Direito de família, Rio de Janeiro: Forense, 1968; e Sucessões, Rio de Janeiro: Forense, 1970. V. GOMES, Orlando. Curriculum Vitae. In: Faculdade de Direito da Universidade Federal da Bahia. Estudos jurídicos em homenagem ao Professor Orlando Gomes, Rio de Janeiro: Forense, 1979, p. IX/XII.
} 


\begin{abstract}
burocracia na relação Estado-cidadão?
Pedro Romano Martinez - Em Portugal, a situação é diferente do que se dá no Brasil. Temos tribunais do Trabalho, mas estes não possuem autonomia, fazem parte da jurisdição comum. O tribunal do Trabalho não tem um juiz que só conhece de questões trabalhistas, porque o respectivo juiz já tratou ou tratará de outras questões, como de família ou de comércio. Por isso, permita-me aqui uma visão, diria, mais alargada do Direito do que a existente em um sistema como o do Brasil. Claro que há sempre vantagem em se ter um juiz especializado, que sempre está vinculado a uma determinada área do Direito. A questão da especialização é positiva ao se imaginar que o juiz terá conhecimentos mais aprofundados sobre um tema a respeito do qual ele o examina de modo exclusivo. A dúvida é se a especialização em uma área como o Direito do Trabalho - que tem evidentemente vantagens posteriormente não trará a desvantagem de impedir a conexão com os princípios estruturantes do Direito, o que seria, por vezes, contraproducente". ${ }^{3}$
\end{abstract}

Em alguns países, essa inter-relação é tão grande que a regulação do direito do trabalho também se encontra dentro do Código Civil, tal como se passa na Itália, p. ex.

Em sentido semelhante, já tivemos a oportunidade de defender esse necessário e profícuo diálogo entre o sistema de direito privado, que tem seu centro de referência no Código Civil, com o microssistema de direito do trabalho, que tem seu centro de referência na CLT - Consolidação das Leis do Trabalho. ${ }^{4}$

Isto porquê, é justamente essa inter-relação que permite ao Direito configurar-se efetivamente em um sistema, sendo a noção de sistema o que the confere cientificidade, ao permitir que as respostas encontradas não sejam arbitrárias, é dizer, possam ser racionalmente replicadas.

Nesse sentido, e assim pontuamos a esse respeito, com isso, consagra-se a própria ideia de sistema, que, como pontua Canaris, deve possuir duas características essenciais: a da ordenação e da unidade. ${ }^{5}$ É dizer, falar-se em sistema significa trabalhar-se com a ideia de unidade, no sentido de junção de conhecimentos variados, e trabalhar-se também com a ideia de ordenação, no sentido de concatenação ${ }^{6}$ (coordenação) desse conjunto de conhecimentos variados, sendo essas características pressupostos da natureza científica da jurisprudência. ${ }^{7}$

Assim, é justamente essa ideia de sistema ${ }^{8}$ que confere cientificidade ao Direito, fazendo com que se possa nominá-lo como ciência [Ciência do Direito]. ${ }^{9}$ Por isso, há quem defenda que trazer

\footnotetext{
3 Pedro ROMANO MARTINEZ, Pedro (Entrevista). Deixar o Direito do Trabalho alheio ao Direito Civil não é benéfico. Consultor Jurídico, $1^{\circ}$ jan. 2017. Disponível em: https://www.conjur.com.br/2017-jan-01/entrevistapedro-romano-martinez-diretor-universidade-lisboa. Acesso em: set. 2019.

${ }_{4}^{4}$ Cfr. RODOVALHO, Thiago. Princípios do direito privado e o registro de imóveis no Brasil, In: BATISTA, Alexandre Jamal (Org.). Princípios, cláusulas gerais e conceitos jurídicos indeterminados nos institutos de direito privado: homenagem ao Professor Doutor Francisco José Cahali. São Paulo: IASP, 2017, p. 214/216.

${ }^{5}$ CANARIS, Claus-Wilhelm. Pensamento sistemático e conceito de sistema na ciência do direito. 4. ed. Lisboa: Fundação Calouste Gulbenkian, 2008, § 1.․, I, p. 12, e § 2..- II 2, p. 77/79.

${ }^{6}$ LARENZ, Karl. Metodologia da ciência do Direito. 3. ed. Lisboa: Fundação Calouste Gulbenkian, 1997, VI, 1, a, p. 622: A "exposição de um modo ordenado, que possibilite a visão de conjunto - quer dizer, na forma de um sistema - é uma das tarefas mais importantes da Jurisprudência científica".

${ }^{7}$ CANARIS, Claus-Wilhelm. Pensamento sistemático e conceito de sistema na ciência do direito. 4. ed. Lisboa: Fundação Calouste Gulbenkian, 2008, § 1.․, I, 1, p. 18.

${ }^{8}$ Sobre a ideia e conceito de sistema, v. FERRAZ JUNIOR, Tercio Sampaio. Conceito de sistema no direito. São Paulo: Revista dos Tribunais, 1976, p. 7/38.

${ }^{9}$ LARENZ, Karl. Metodologia da ciência do Direito. 3. ed. Lisboa: Fundação Calouste Gulbenkian, 1997, VI, 1, a, p. 622: "Um tal sistema garante em ampla medida não só a clareza, mas também a segurança jurídica; porque, nos quadros de um tal sistema, se ele fosse "completo", poder-se-ia dar a toda a questão jurídica uma resposta, por via de operação lógica do pensamento. Garante a ausência de contradição lógica de todas as consequências dele derivadas e com isso, segundo parece, a "cientificidade" da Jurisprudência, no sentido do conceito
} 
a ideia de sistema para o direito foi a maior contribuição do jusnaturalismo ao direito privado europeu, ${ }^{10}$ experimentando grande evolução científica ao longo do século XIX, ${ }^{11}$ especialmente com Friedrich Carl von Savigny, e sua clássica obra System des heutigen Römischen Rechts.

Sendo que a noção de sistema não só confere cientificidade ao Direito, como se traduz, ainda, em elemento que também lhe confere segurança [segurança jurídica] e o torna apto à realização de seus valores ${ }^{12-13}$

Esses prolegômenos são feitos pois, no tema ora sub examine, esse diálogo entre Direito do Trabalho e Direito Civil é absolutamente inevitável, haja vista que se controverte justamente sobre a aplicação de uma categoria de direito privado, é dizer, a responsabilidade civil por fato de outrem prevista no CC art. 932, inciso III.

\section{ESTADO DEMOCRÁTICO DE DIREITO E O EXERCÍCIO DO PODER JUDICIÁRIO. PROCEDIMENTO E FUNDAMENTAÇÃO COMO PRESSUPOSTOS DE LEGITIMAÇÃO À ATUAÇÃO DEMOCRÁTICA DO PODER JUDICIÁRIO}

Tomamos a liberdade, ainda à guisa de introdução, de tecer mais algumas palavras perambulares, mas que nos parecem necessárias, sobre a própria legitimidade do exercício do Poder Judiciário. ${ }^{14}$

Nesse sentido, um ponto que por vezes passa ao largo, de forma quase que irrefletida, é sobre o exercício dos poderes que compõem nossa República.

cientificista de ciência". V., também, CANARIS, Claus-Wilhelm. Pensamento sistemático e conceito de sistema na ciência do direito. 4. ed. Lisboa: Fundação Calouste Gulbenkian, 2008, § 1.‥, I, 1, p. 15/16.

10 FERRAZ JUNIOR, Tercio Sampaio. Conceito de sistema no direito. São Paulo: Revista dos Tribunais, 1976, p. 15.

${ }^{11}$ FERRAZ JUNIOR, Tercio Sampaio. Conceito de sistema no direito. São Paulo: Revista dos Tribunais, 1976, p. 26.

12 CANARIS, Claus-Wilhelm. Pensamento sistemático e conceito de sistema na ciência do direito. 4. ed. Lisboa: Fundação Calouste Gulbenkian, 2008, $\S 1 .^{\circ}$, I, 2, p. 22: "Longe de ser uma aberração, como pretendem os críticos do pensamento sistemático, a idéia do sistema jurídico justifica-se a partir de um dos mais elevados valores do Direito, nomeadamente do princípio da justiça e das suas concretizações no princípio da igualdade e na tendência para a generalização. Acontece ainda que outro valor supremo, a segurança jurídica, aponta na mesma direcção. Também ela pressiona, em todas as suas manifestações - seja como determinabilidade e previsibilidade do Direito, como estabilidade e continuidade da legislação e da jurisprudência ou simplesmente como praticabilidade da aplicação do Direito - para a formação de um sistema, pois todos esses postulados podem ser muito melhor prosseguidos através de um Direito adequadamente ordenado, dominado por poucos e alcançáveis princípios, portanto um Direito ordenado em sistema, do que por uma multiplicidade inabarcável de normas singulares desconexas e em demasiado fácil contradição umas com as outras. Assim, o pensamento sistemático radica, de facto, imediatamente, na idéia de Direito (como o conjunto dos valores jurídicos mais elevados)".

${ }^{13}$ A esse respeito, cfr. RODOVALHO, Thiago. Princípios do direito privado e o registro de imóveis no Brasil, In: BATISTA, Alexandre Jamal (Org.). Princípios, cláusulas gerais e conceitos jurídicos indeterminados nos institutos de direito privado: homenagem ao Professor Doutor Francisco José Cahali. São Paulo: IASP, 2017, p. 214/215. V., também, NUNES FRITZ, Karina. Comentário ao EREsp. 1.280.825/RJ: prazo prescricional de dez anos para responsabilidade contratual? Revista IBERC, Minas Gerais, v. 2, n.1, jan./abr. 2019, p. 7/10.

${ }^{14}$ Cfr. LUHMANN, Niklas. Legitimação pelo procedimento. Brasília: UnB, 1980, Parte I, Cap. II, p. 30: "Pode definir-se a legitimidade como uma disposição generalizada para aceitar decisões de conteúdo ainda não definido, dentro de certos limites de tolerância [...] como que uma satisfação interior quanto a uma troca de obediência contra uma 'participação democrática' - ou se essa disposição é o resultado dum elevado número de mecanismos sociais que identificam conjunturas muito heterogêneas de motivos". 
O Brasil, como sói acontecer na ampla maioria dos países ocidentais democráticos, tem a sua República composta por três Poderes: Executivo, Legislativo e Judiciário, independentes e harmônicos entre si (CF art. 2.․).

Os três, como lhes é inerente, exercem uma forma de «poder». Deste modo, Poder Judiciário também é exercício de poder. Contudo, a legitimidade desse exercício não Ihes é, entre os três poderes, uniforme.

Assim, Poderes Executivo e Legislativo haurem a legitimidade do seu exercício de poder e força do voto popular, manifestado de forma livre e democrática. Entretanto, assim não se passa com o Poder Judiciário, ao contrário do que ocorre em algumas democracias ocidentais, especialmente de common law.

Nos EUA, p. ex., juízes (como regra) são eleitos, de sorte que igualmente auferem sua legitimidade do voto popular.

Seria um equívoco tentar avaliar qual modelo é melhor. Cada um tem suas virtudes e defeitos. ${ }^{15}$ Cabe avaliar qual é mais adequado a essa ou aquela determinada cultura.

Em nosso país, a regra é o ingresso técnico para a magistratura, o que se dá através do concurso público (a exceção fica por conta dos Tribunais Superiores e do Quinto Constitucional). ${ }^{16}$ Culturamente, parece-nos ser o melhor modelo para o nosso país. Contudo, avulta uma grande diferença entre eles.

No modelo do voto popular, com os defeitos que possui, o juiz extrai sua legitimidade justamente desse voto, daí não ser estranho que, nesses países, admitam-se, p. ex., e se conviva com isso, decisões não-fundamentadas, o que, para nós, parece absolutamente inadmissível.

E a ausência do voto popular não quer significar que o modelo brasileiro não possui raiz democrática, como, por vezes, de tempos em tempos, especialmente em épocas de crise, aqui ou acolá, sugerem os críticos. ${ }^{17}$

Ao revés, os juízes brasileiros haurem sua legitimidade democrática doutras fontes, são elas: (i) procedimento; e (ii) fundamentação. Daí a importância de que gozam, procedimento e fundamentação, em nosso sistema jurídico, guindados que são a mandamentos constitucionais (CF art. 5. ${ }^{\circ}$ incs. LIV e art. 93 inc. IX).

Esses dois fatores - procedimento e fundamentação - viabilizam o controle e a participação democrática, conferindo, portanto, legitimidade a esse exercício de um dos Poderes de República.

\footnotetext{
${ }^{15}$ Para uma crítica ao modelo estadunidense, v. RODRIGUES, Francisco Cesar Pinheiro. Juízes decidem a favor de seus "apoiadores". Consultor Jurídico, 18 set. 2009. Disponível em: https://www.conjur.com.br/2009-ago18/juizes-eleitos-povo-eua-decidem-favor-apoiadores. Acesso em: set. 2019; e MELO, João Ozório de. Campanhas eleitorais de juízes ficam mais politizadas nos EUA. Consultor Jurídico, 16 ago. 2017 Disponível em: https://www.conjur.com.br/2017-ago-16/campanhas-eleitorais-juizes-ficam-politizadas-eua. Acesso em: set. 2019. ${ }^{16}$ Sobre o modelo adotado no Brasil, cfr., entre outros, BARBI, Celso Agrícola. Formação, seleção e nomeação de juízes no Brasil, sob o ponto de vista da humanização da justiça. In: ALVIM, Arruda (Dir.). Revista de Processo, São Paulo: Revista dos Tribunais, v. 11 e 12, jul./dez. 1978, p. 31/36, em especial, p. 34; e BANDEIRA, Regina Maria Groba. Seleção dos magistrados no direito pátrio e comparado. Viabilidade legislativa de eleição direta dos membros do Supremo Tribunal Federal (Estudo), Brasília: Câmara dos Deputados, 2002, p. $3 / 10$.

17 V., p. ex., a consulta feita por SADER, Emir. Consulta: juízes devem ser eleitos pelo voto popular? Carta Capital, 26 fev. 2009. Disponível em: https://www.cartamaior.com.br/?/Blog/Blog-do-Emir/Consulta-juizes-devemser-eleitos-pelo-voto-popular-/2/23992. Acesso em: set. 2019.
} 
Deste modo, é através do rigoroso respeito ao due process of law, em toda sua magnitude e com princípios que o compõem (Princípio do Juiz Natural, Princípio da Imparcialidade do Juiz, Princípio da igualdade ou isonomia Princípio do contraditório e princípio da ampla defesa, Princípio do livre convencimento motivado ou persuasão racional, Princípio da Motivação ou fundamentação, Princípio da Publicidade, Princípio da lealdade processual, Princípio da boa-fé, Princípio da cooperação, Princípio do Duplo Grau de Jurisdição, Princípio da economia processual e da instrumentalidade das formas), e que democraticamente se controla a atividade jurisdicional.

Nesse sentido, vêm a calhar as ensinanças de Niklas Luhmann a esse respeito, para quem:

\begin{abstract}
"[o] procedimento não constitui um critério de verdade mas favorece a correção da decisão; que possibilita e canaliza a comunicação, que garante a realização das decisões, independentemente do fato de que a lógica funcione, e permita ou não os cálculos apenas das soluções exatas; e que contribui para abolir as perturbações previsíveis"; 18 [os procedimentos] "eliminam alternativas, reduzem a complexidade, absorvem a incerteza ou transformam a complexidade indeterminada de todas as probabilidades numa problemática determinável e compreensível. É-Ihes atribuída a seletividade duma comunicação. Ela empresta-Ihes o sentido", 19 evitando considerar aspectos alheios ao processo. ${ }^{20}$
\end{abstract}

Disso avulta, e por isso a destacamos inclusive como elemento autônomo, a fundamentação. A razão pela qual, ao contrário do que se passa em alguns países de common law, que, como já dito, admitem decisões não-fundamentadas, a motivação é tão importante, possuindo assento constitucional, é justamente porque ela interessa inclusive para além das partes. É o diálogo democrático que o juiz mantém com a sociedade.

Ao fundamentar, o juiz dialoga com a sociedade e, com isso, permite-lhe a participação democrática. É através da fundamentação que o juiz explica e justifica as razões de seu convencimento, demonstrando que não advêm de uma arbitrariedade, e sim de uma interpretação sistematicamente extraída do ordenamento jurídico e replicável.

A legitimidade de uma Corte advém outrossim da qualidade de sua argumentação. Assim, «argumentar é legitimar». Exatamente por isso, é preciso sempre buscar compreender a lógica («sistemática») do dispositivo, sua ratio essendi, para fundamentar. Fugir disso é argumentar de forma casuística e arbitrária.

Nesse contexto, já tivemos oportunidade de criticar, para demonstrar essa relevância do dever de fundamentar, a polêmica suscitada pela decisão proferida no caso do jogador Richarlysson, em que o juiz, entre outras passagens muito questionáveis, afirmou que "Já que foi colocado, como lastro, este Juízo responde: futebol é jogo viril, varonil, não homossexual". ${ }^{21}$ É a fundamentação que permite separar o que é visão pessoal do julgador, arbitrária, portanto, daquilo que é uma exegese jurídica que pode ser racionalmente extraída do sistema jurídico. ${ }^{22}$

\footnotetext{
18 LUHMANN, Niklas. Legitimação pelo procedimento. Brasília: UnB, 1980, Parte I, Cap. I, p. 17.

${ }^{19}$ LUHMANN, Niklas. Legitimação pelo procedimento. Brasília: UnB, 1980, Parte I, Cap. III, p. 38.

20 LUHMANN, Niklas. Legitimação pelo procedimento. Brasília: UnB, 1980, Parte II, Cap. I, p. 56.

${ }^{21}$ A decisão pode ser conferida em https://www.conjur.com.br/2007-ago-

03/juiz_nega_acao_jogador_futebol_macho.

22 RODOVALHO, Thiago. Das Rechtsstaatsprinzip (O princípio do estado democrático de direito) e a segurança jurídica. In: ALVIM, Arruda et allii (Dirs.). Revista Forense (Impresso), Rio de Janeiro: Forense, v. 415, jan./jun.
} 
Deste modo, ao juiz não é dado um poder supremo e ilimitado de decidir sem qualquer parâmetro mínimo em seu discurso jurídico, não havendo, portanto, discricionariedade plena ou absoluta no exercício de seu mister, como, aliás, não há a nenhum exercício de Poder em um Estado Democrático de Direito. ${ }^{23}$ Ao revés, deve, por óbvio, decidir conforme seu livre convencimento motivado, mas dentro e a partir do ordenamento jurídico [interpretatio intra ius], o que implica dizer dentro e a partir do padrão de racionalidade que é dado ou permitido pelo discurso jurídico.

E esse controle de correção e racionalidade se dá justamente pela legitimação que the confere o procedimento, e pela fundamentação ${ }^{24}$ e motivação da decisão (estruturação da interpretação), ${ }^{25}$ permitindo, ambos - procedimento e fundamentação -, conjugados entre si, o controle conteudístico da decisão, de modo a demonstrar-se que aquela decisão proferida consubstanciava-se efetivamente numa decisão válida. ${ }^{26-27}$

Por fim, reiteramos que tomamos a liberdade de fazer essa breve digressão, pois a quaestio iuris posta neste objeto de estudo (responsabilidade civil por fato de outrem) envolve necessariamente um diálogo com o Direito Civil (a que aludimos no item anterior) e, além disso, uma interpretação que envolve um raciocínio por analogia ou ao menos extensivo, ${ }^{28}$ uma vez que o texto normativo do CC art. 932 inciso III alude a empregador ou comitente, nada dispondo sobre contrato terceirizado, de tal sorte que saber quando e como essa extensão é possível atrai para si um ônus argumentativo maior.

\section{CC ART. 932 INCISO III. CONSAGRAÇÃO DA RESPONSABILIDADE CIVIL POR FATO DE OUTREM. NORMA QUE ALUDE A EMPREGADOR OU COMITENTE. HERMENÊUTICA JURÍDICA PARA SABER QUANDO E COMO PODE SER ESTENDIDO AO CONTRATO DE PRESTAÇÃO DE SERVIÇOS POR TERCEIRIZADA}

O Código Civil brasileiro adota, como regral geral, o princípio da culpa, insculpido na responsabilidade civil subjetiva (= responsabilidade direta ou por fato próprio e culposo), disciplinado

2012, p. 291/315, em especial, cap. 5: Subprincípio da segurança jurídica: a confiança do particular. O Problema da Segurança Jurídica/Confiança do Particular e a Racionalidade das Decisões Judiciais, p. 305/312.

${ }^{23}$ Sobre o tema, cfr. ARRUDA ALVIM, Teresa. Recurso especial, recurso extraordinário e ação rescisória. 2. ed. São Paulo: Revista dos Tribunais, 2008, n. 7.2, p. 186 et seq.

${ }^{24}$ Sobre racionalidade e fundamentação, cfr. a crítica feita por STEIN, Ernildo. Racionalidade e existência: o ambiente hermenêutico e as ciências humanas. 2. ed. ljuí: Unijuí, 2008, Cap. 4, p. 74.

${ }^{25}$ ARRUDA ALVIM, Teresa. Recurso especial, recurso extraordinário e ação rescisória. 2. ed. São Paulo: Revista dos Tribunais, 2008, n. 1.4, p. 29/30.

${ }_{26}$ CASTANHEIRA NEVES, António. Questão-de-facto-Questão-de-direito ou o problema metodológico da juridicidade (ensaio de uma reposição crítica). Coimbra: Almedina, 1967, § 15.ํ, 1, b, p. 367.

${ }_{27}$ RODOVALHO, Thiago. Das Rechtsstaatsprinzip (O princípio do estado democrático de direito) e a segurança jurídica. In: ALVIM, Arruda et allii (Dirs.). Revista Forense (Impresso), Rio de Janeiro: Forense, v. 415, jan.jjun. 2012, p. 310/311.

${ }^{28}$ Analogia é a extensão provável do conhecimento mediante o uso de semelhanças que se podem moldar a diferentes situações (ABBAGNANO, Nicola. Diccionario de filosofía. 4. ed. México: Fondo de Cultura Económica, 2004, p. 72, em tradução livre). Para tanto, no Direito, é preciso que haja semelhança relevante e que não haja distinção importante entre o caso disciplinado pela lei e o caso a que se pretende estender o raciocínio (a esse respeito, v., entre outros, BOBBIO, Norberto. Teoria do ordenamento jurídico. 10. ed. Brasília: UnB, 1999, p. 151/155; FERRAZ JUNIOR, Tercio Sampaio. Conceito de sistema no direito. São Paulo: Revista dos Tribunais, 1976, p. 315/316; e LAMARTINE CORREA, J.. Conceito da pessoa jurídica, Curitiba: [S.ed.], 1962, p. 164/165. 
em seu art. 186. ${ }^{29-30}$ Demais disso, o CC/02 traz uma cláusula geral de responsabilidade civil objetiva, normatizada em seu art. 927 par. ún., ${ }^{31}$ e complementada pelo art. 931, além de aprimorar a responsabilização civil por abuso de direito (arts. 927 caput c/c art. 187). ${ }^{32}$

E, para uma maior amplitude do sistema de responsabilização civil, o Código Civil prevê, ainda, em seu art. 932, incisos I a V, hipóteses em que alguém pode vir a responder por fato de outrem, rompendo com a regra geral de que cada um só responde por seus próprios atos. ${ }^{33}$ Justamente por ser um rompimento com essa regra geral, consubstancia-se em situação excepcional, ${ }^{34}$ a demandar rigorosa análise do preenchimento de seus pressupostos, lembrando aqui o clássico adágio segundo o qual norma restritiva de direito há de ser interpretada restritivamente. ${ }^{35}$

Em razão disso, é que Menezes Direito e Cavalieri Filho advertem que essa responsabilização excepcional por fato de outrem não pode ocorrer de forma arbitrária e indiscriminada ${ }^{36}$ especialmente porque estamos falando de uma responsabilização extracontratual objetiva e solidária (lembrando que solidariedade não se presume) ${ }^{37}$ por fato de terceiro.

Nesse contexto, é preciso analisar o inciso III do art. 932 do CC, precisamente o inciso objeto da quaestio iuris posta no presente estudo, para compreender seus fundamentos e pressupostos, para então aferir-se quando e como é possível sua extensão a hipóteses não previstas no texto normativo.

Assim, diz o CC art. 932 inc. III:

${ }^{29}$ Art. 186. Aquele que, por ação ou omissão voluntária, negligência ou imprudência, violar direito e causar dano a outrem, ainda que exclusivamente moral, comete ato ilícito.

30 Cfr LIMA, Alvino. A responsabilidade civil pelo fato de outrem. Rio de Janeiro: Forense, 1973, p. 17/20; e CAVALIERI FILHO, Sergio. Programa de responsabilidade civil. 11. ed. São Paulo: Atlas, 2014, p. 235.

${ }^{31}$ Art. 927. Parágrafo único. Haverá obrigação de reparar o dano, independentemente de culpa, nos casos especificados em lei, ou quando a atividade normalmente desenvolvida pelo autor do dano implicar, por sua natureza, risco para os direitos de outrem.

${ }^{2}$ Art. 927. Aquele que, por ato ilícito (arts. 186 e 187), causar dano a outrem, fica obrigado a repará-lo.

Art. 187. Também comete ato ilícito o titular de um direito que, ao exercê-lo, excede manifestamente os limites impostos pelo seu fim econômico ou social, pela boa-fé ou pelos bons costumes. A esse respeito, RODOVALHO, Thiago. Abuso de direito e direitos subjetivos, São Paulo: Revista dos Tribunais, 2011, passim.

33 LIMA, Alvino. A responsabilidade civil pelo fato de outrem. Rio de Janeiro: Forense, 1973, p. 27: "a responsabilidade civil pelo fato de outrem se verifica todas as vezes em que alguém responde pelas conseqüências jurídicas de um ato material de outrem, ocasionando ilegalmente um dano a terceiros. Em matéria de responsabilidade pelo fato de outrem, a reparação do dano cabe a uma pessoa que é materialmente estranha a sua realização".

${ }_{34}$ MENEZES DIREITO, Carlos Alberto; CAVALIERI FILHO, Sergio. Comentários ao novo Código Civil: da responsabilidade civil. Das preferências e privilégios creditórios (arts. 927 a 965). In: TEIXEIRA, Sálvio de Figueiredo (Coord.). Comentários ao novo Código Civil. Rio de Janeiro: Forense, 2004, v. XIII, coment. 1 ao CC art. 932, p. 196/197: "Temos, nos incisos I a V do dispositivo, hipóteses de responsabilidade por fato de outrem. São situações excepcionais, porque a regra é que cada um responde por seus próprios atos. É o que tem sido chamado de responsabilidade direta ou responsabilidade por fato próprio, cuja justificativa está no próprio princípio informador da teoria da reparação. Apenas excepcionalmente uma pessoa pode vir a responder pelo fato de outrem" (destacamos). V. também LIMA, Alvino. A responsabilidade civil pelo fato de outrem. Rio de Janeiro: Forense, 1973, p. 20/21; CAVALIERI FILHO, Sergio. Programa de responsabilidade civil. 11. ed. São Paulo: Atlas, 2014, p. 235; e SERPA LOPES, Miguel Maria de. Curso de direito civil: fontes acontratuais das obrigações. Responsabilidade civil. 4. ed. Rio de Janeiro: Freitas Bastos, 1995, v. 5, p. 239.

${ }^{35}$ MAXIMILIANO, Carlos. Hermenêutica e aplicação do direito. 16. ed. Rio de Janeiro: Forense, 1997, p. 313.

36 MENEZES DIREITO, Carlos Alberto; CAVALIERI FILHO, Sergio. Comentários ao novo Código Civil: da responsabilidade civil. Das preferências e privilégios creditórios (arts. 927 a 965). In: TEIXEIRA, Sálvio de Figueiredo (Coord.). Comentários ao novo Código Civil. Rio de Janeiro: Forense, 2004, v. XIII, coment. 1 ao CC art. 932, p. 197. Cfr., ainda, CAVALIERI FILHO, Sergio. Programa de responsabilidade civil. 11. ed. São Paulo: Atlas, 2014, p. 235.

${ }^{37} \mathrm{CC}$ art. 265. A solidariedade não se presume; resulta da lei ou da vontade das partes. 
"Art. 932. São também responsáveis pela reparação civil:

I - os pais, pelos filhos menores que estiverem sob sua autoridade e em sua companhia;

II - o tutor e o curador, pelos pupilos e curatelados, que se acharem nas mesmas condições;

III - o empregador ou comitente, por seus empregados, serviçais e prepostos, no exercício do trabalho que Ihes competir, ou em razão dele" (destacamos).

Pelo texto normativo, responsabiliza-se, no inc. III, na primeira hipótese, o empregador. Assim, não há dúvidas de que é preciso se subsumir à categoria de empregador, i.e., com o preenchimento dos requisitos legais previstos, e, cumulativamente exigidos, no art. $3 . .-$ da CLT para a configuração do elo empregatício entre as partes, quais sejam: subordinação hierárquica, dependência econômica e serviços prestados de maneira não eventual. ${ }^{38}$

A segunda hipótese prevista no inc. III do CC art. 932 diz respeito ao comitente, sendo que, como regra, a relação jurídica havida entre a empresa terceirizada e a terceirizadora não pode ser caracterizada como um contrato de comissão, que possui requisitos específicos previstos no CC arts. 693 e ss. $^{39}$

Pois bem, não se tratando, portanto, nem de empregador nem de comitente, trata-se, por via de consequência, de raciocínio per analogiam ou ao menos per extensio, de sorte a demandar a análise de quando e como essa extensão é juridicamente possível.

Deste modo, tem-se que, quando se analisa o inciso III do art. 932 do CC, o fundamento jurídico dessa excepcional responsabilização por fato de outrem é a relação de subordinação entre o agente causador do dano e o terceiro a quem se pretende imputar a aludida responsabilização, ${ }^{40} \mathrm{o}$ que, aliás, é igualmente o fundamento também da responsabilidade por fato de outrem imputada aos pais (inc. I) ou aos tutores e curadores (inc. II), ${ }^{41}$ a evidenciar que essa responsabilização por fato de outrem tem como ratio essendi a relação ou vínculo jurídico de subordinação, havendo, inclusive,

38 "Por subordinação jurídica entende-se um estado de dependência real criado por um direito do empregador de comandar, dar ordens, donde nasce a obrigação correspondente do empregado de se submeter a essas ordens" (MARANHÃO, Délio; CARVALHO, Luiz Inácio B. Direito do trabalho. 17. ed. São Paulo: FGV, 1998, p. 64).

39 "Pelo contrato de comissão, uma pessoa, denominada comissário, adquire ou vende bens em nome próprio, mas por conta de outrem, chamado comitente. Configura-se, assim, a comissão "pela assunção da obrigação de colocação ou de aquisição de bens, a favor de outrem, contratando o comissário com terceiros, em nome de sua firma ou da pessoa jurídica correspondente, de sorte que o comitente nenhuma relação jurídica com aqueles estabelece [...] O objeto do contrato de comissão consiste, pois, na aquisição ou venda de bens por conta do comitente, mas em nome do comissário. Note-se que o comissário sequer precisa declarar o nome do comitente ao celebrar o contrato com terceiro, sendo, inclusive, muitas vezes, proibido de fazê-lo por força do próprio contrato de comissão. De toda sorte, o comitente é o verdadeiro dono do negócio, aquele por conta de quem a operação se realiza [...] Considera-se o contrato intuitu personae, por se fundar na confiança recíproca das partes. Por esta razão, não pode o comissário delegar a execução da comissão a outrem se o comitente não o autorizou expressamente; presume-se que sua escolha se deve à diligência e habilidade próprias do comissário" (TEPEDINO, Gustavo. Das várias espécies de contrato. Do Mandato. Da Comissão. Da agência e distribuição da corretagem. Do transporte (arts. 653 a 756). In: TEIXEIRA, Sálvio de Figueiredo (Coord.) Comentários ao novo Código Civil. Rio de Janeiro: Forense, 2008, v. X, p. 209/210 e 213). Em sentido próximo, PONTES DE MIRANDA, Francisco Cavalcanti. Tratado de Direito Privado: Parte Especial (Direito das Obrigações. Mandato. Gestão de negócios alheios sem outorga. Mediação. Comissão. Corretagem). 3. ed. Rio de Janeiro: Borsoi, 1972, t. XLIII, p. 283/286.

40 Cfr. GOMES, Orlando. Obrigações. 12. ed. Rio de Janeiro: Forense, 1999, p. 290.

41 Ainda que haja, evidentemente, distinções entre a responsabilidade de pais, tutores e curadores e a responsabilidade do comitente (cfr. LIMA, Alvino. A responsabilidade civil pelo fato de outrem. Rio de Janeiro: Forense, 1973, p. 52). 
quem defenda ser esse vínculo de subordinação (ou preposição) o critério principal, senão único para fundamentar a responsabilização do empregador ou comitente..$^{42}$

Logo, «essa» é a pedra de toque a admitir ou não o raciocínio extensivo.

Esse era o sentido possível para o raciocínio per analogiam ou ao menos per extensio defendido desde a doutrina clássica sobre o tema. Assim, naquela que talvez seja a obra mais importante sobre o assunto já escrito no país, defendia Alvino Lima:

\begin{abstract}
"As condições ou requisitos necessários à caracterização da responsabilidade civil pelo fato de outro são: a) a existência de uma relação entre o civilmente responsável e o autor material do ato danoso; b) o caráter culposo do fato danoso; c) uma relação entre a função e o fato danoso.

Passemos ao exame de cada um desses requisitos.

a) Entre o autor material do dano causado a terceiro e o civilmente responsável, deve existir um laço de submissão, de dependência, que já tivemos oportunidade de descrever (n.. 17). Trata-se de relação entre o comitentes e o preposto, aquele exercendo sobre este o poder de dar ordens, instruções, dirigindo a maneira de cumprir as funções que lhe são conferidas. Caracteriza-se este primeiro requisito pelo direito ou poder de direção, de fiscalização e de controle do comitente sobre $o$ preposto no exercício de uma função determinada, exercida por conta e risco e no proveito ou no interesse do comitente.

$[\ldots]$

A subordinação não se refere à direção técnica, mas ao poder de organização econômica do empregador. Conforme se verifica das considerações expostas, o critério da subordinação não é eliminado nem substituído por outro". ${ }^{43}$
\end{abstract}

Esse entendimento era compartilhado pela doutrina clássica sobre o tema:

\begin{abstract}
"Essa modalidade de responsabilidade complexa não compreende todas as categorias de prestação de serviços, mas unicamente as que se caracterizam pelo vínculo de preposição [...] Preposto é aquele que está sob a vinculação de um contrato de preposição, isto é, um contrato em virtude do qual certas pessoas exercem, sob a autoridade de outrem, certas funções subordinadas, no seu interesse e sob suas ordens e instruções, e que tem o dever de fiscalizá-la e vigiá-la, para que proceda com a devida segurança, de modo a não causar dano a terceiros [...] é preciso que concorram três requisitos, cuja prova incumbe ao lesado: a. qualidade de empregado, serviçal ou preposto, do agente do ato; $b$. procedimento com culpa (dolo, negligência, imprudência, ou imperícia) desse agente; c. que o ato lesivo tenha sido praticado no exercício da função que Ihe competia, ou em sua ocasião" ${ }^{44}$
\end{abstract}

Bem como, ainda o é pela doutrina moderna:

\footnotetext{
${ }^{42}$ MELO, Albertino Daniel de. A responsabilidade civil pelo fato de outrem nos direitos francês e brasileiro. Rio de Janeiro: Forense, 1972, p. 46. V., ainda, SERPA LOPES, Miguel Maria de. Curso de direito civil: fontes acontratuais das obrigações. Responsabilidade civil. 4. ed. Rio de Janeiro: Freitas Bastos, 1995, v. 5, p. 244: "O que há de principal nessas relações entre comitente e preposto é o vínculo hierárquico de subordinação (cfr. vol. IV, no 419, letra C, págs. 114-115)".

${ }^{43}$ LIMA, Alvino. A responsabilidade civil pelo fato de outrem. Rio de Janeiro: Forense, 1973, p. 55/56.

${ }^{44}$ CHAVES, Antonio. Tratado de direito civil: responsabilidade civil. São Paulo: Revista dos Tribunais, 1985 , v. 3 , p. 97/98. No mesmo sentido, CARVALHO SANTOS, J. M. Código Civil brasileiro interpretado: direito das obrigações (arts. 1505 a 1532), Rio de Janeiro: Freitas Bastos, 1961, v. XX, p. 226/227; SERPA LOPES, Miguel Maria de. Curso de direito civil: fontes acontratuais das obrigações. Responsabilidade civil. 4. ed. Rio de Janeiro: Freitas Bastos, 1995, v. 5, p. 244; MAIA, Paulo Carneiro. Responsabilidade dos preponentes pela atuação de seus prepostos. In: MAIA, Paulo Carneiro (Org.). Estudos de direito civil. Rio de Janeiro: Alba, 1962, p. 121/122; e AGUIAR DIAS, José de. Da responsabilidade civil. 5. ed. Rio de Janeiro: Forense. 1973, v. II, p. 161/176 (em especial, p. 161/162 e 166/167);
} 


\begin{abstract}
"No que toca ao empregador ou preponente, sempre alguém com poder de direção sobre a atividade de outrem, que the é subordinado e the tem relação de dependência [...] É certo, vale o acréscimo, que o conceito de preposição vem sendo alargado pela jurisprudência, sem dúvida, e acertadamente, para excluir a necessidade de vínculo empregatício, mas sempre à consideração de que exista uma relação de subordinação, de direção, como sucede, por exemplo, com o médico cirurgião e sua equipe". 45
\end{abstract}

Inclusive além-mar, como se observa na clássica obra de Pires de Lima e Antunes Varela: "A comissão pressupõe uma relação de dependência entre o comitente e o comissário, que autorize aquele a dar ordem ou instruções a este. Só essa possibilidade de direcção é capaz de justificar a responsabilidade do primeiro pelos actos do segundo". ${ }^{46}$

E dele não discrepa a jurisprudência pátria, que somente vem admitindo a extensão da responsabilização objetiva e solidária por fato de outrem quando presente o vínculo de subordinação.

Justamente por isso, está correta a vetusta Súmula n. 341 do Supremo Tribunal Federal, que diz que é presumida a culpa do patrão ou comitente pelo ato culposo do empregado ou preposto. Ela alude a essa relação de subordinação que há no emprego ou na preposição.

De igual sorte, está correta a Súmula no 331 do Tribunal Superior do Trabalho. Primeiro, ao vedar que possa haver, na terceirização lícita, a pessoalidade e a subordinação direta ("III - Não forma vínculo de emprego com o tomador a contratação de serviços de vigilância (Lei no 7.102, de 20.06.1983) e de conservação e limpeza, bem como a de serviços especializados ligados à atividademeio do tomador, desde que inexistente a pessoalidade e a subordinação direta"). Segundo, precisamente por não haver, por via de consequência, vínculo de subordinação, prever a responsabilidade "subsidiária" do tomador de serviços, ${ }^{47}$ e com relação às obrigações trabalhistas, e não com relação ao cometimento de ato ilícito (verbis: "IV - O inadimplemento das obrigações trabalhistas, por parte do empregador, implica a responsabilidade subsidiária do tomador dos serviços quanto àquelas obrigações, desde que haja participado da relação processual e conste também do título executivo judicial [...] VI - A responsabilidade subsidiária do tomador de serviços abrange todas as verbas decorrentes da condenação referentes ao período da prestação laboral').

Em igual sentir, o disposto no $\S 1 . \circ$ do art. 4.--A da Lei ํo 6.019/74, inclú́do pela Lei $n^{\circ}$ $13.429 / 2017,48$ que explicita que o tomador dos serviços terceirizados verdadeiramente não pode

45 GODOY, Claudio Luiz Bueno de. Comentários ao CC art. 932. In: PELUSO, Cezar (Coord.). Código Civil comentado: doutrina e jurisprudência. 12. ed. Barueri: Manole, 2018, p. 905/906; MENEZES DIREITO, Carlos Alberto; CAVALIERI FILHO, Sergio. Comentários ao novo Código Civil: da responsabilidade civil. Das preferências e privilégios creditórios (arts. 927 a 965). In: TEIXEIRA, Sálvio de Figueiredo (Coord.). Comentários ao novo Código Civil. Rio de Janeiro: Forense, 2004, v. XIII, coments. 9 e 10 ao CC art. 932, p. 212/216; CAVALIERI FILHO, Sergio. Programa de responsabilidade civil. 11. ed. São Paulo: Atlas, 2014, p. 247/248; e CARVALHO, Washington Rocha de et allii. Dos atos unilaterais. Dos títulos de crédito. Da responsabilidade civil. Das preferências e privilégios creditórios (arts. 854 a 965). In: ALVIM, Arruda; ALVIM, Thereza (Coords.). Comentários ao Código Civil brasileiro. Rio de Janeiro: Forense, 2013, v. VIII, p. 415.

46 PIRES DE LIMA; ANTUNES VARELA. Código civil anotado (artigos 1.ำ a $761^{\circ}$ ). 4. ed. Coimbra: Coimbra Editora, 1987, v. I, p. 508; No mesmo sentido, ABíLIO NETO. Código Civil anotado. 18. ed. Lisboa: Ediforum, 2013 , p. 556.

47 A esse respeito, cfr. PINTO MARTINS, Sergio. Terceirização no Direito do Trabalho. 15. ed. São Paulo: Saraiva, 2018, p. 176.

${ }^{48} \mathrm{Art} .4^{0}$-A. Considera-se prestação de serviços a terceiros a transferência feita pela contratante da execução de quaisquer de suas atividades, inclusive sua atividade principal, à pessoa jurídica de direito privado prestadora de serviços que possua capacidade econômica compatível com a sua execução. 
realizar qualquer ingerência direta na realização do serviço ("[a] empresa prestadora de serviços contrata, remunera e dirige o trabalho realizado por seus trabalhadores"), ou seja, não pode existir subordinação direta e pessoalidade do empregado terceirizado para com a tomadora, sob pena de se ter a terceirização como ilícita.

\section{CONCLUSÃO}

Deste modo, feitas essas considerações, é preciso aferir se a situação fática do caso concreto se amolda a esses pressupostos legais.

Sendo assim, em não havendo essa relação de subordinação, não é possível estender a responsabilidade civil objetiva e solidária por fato de outrem prevista no CC art. 932, inc. III.

Assim, o tomador poderia ser responsabilizado, subsidiariamente, pelas "obrigações trabalhistas», nos termos da Súmula no 331 do TST, mas não poderia ser responsabilizado, objetiva e solidariamente, pelo cometimento de ato ilícito pela empresa terceirizada, haja vista o nãopreenchimento dos pressupostos legais para a extensão da responsabilidade civil por fato de outrem.

Poder-se-ia cogitar de outras formas de responsabilização, como a responsabilidade subjetiva, por culpa, mas não na responsabilidade civil objetiva e solidária por fato de outrem prevista no CC art. 932, inc. III.

\section{REFERÊNCIAS}

ABBAGNANO, Nicola. Diccionario de filosofía. 4. ed. México: Fondo de Cultura Económica, 2004.

ABÍLIO NETO. Código Civil anotado. 18. ed. Lisboa: Ediforum, 2013.

AGUIAR DIAS, José de. Da responsabilidade civil. 5. ed. Rio de Janeiro: Forense. 1973, v. II.

ARRUDA ALVIM, Teresa. Recurso especial, recurso extraordinário e ação rescisória. 2. ed. São Paulo: Revista dos Tribunais, 2008.

BANDEIRA, Regina Maria Groba. Seleção dos magistrados no direito pátrio e comparado. Viabilidade legislativa de eleição direta dos membros do Supremo Tribunal Federal (Estudo), Brasília: Câmara dos Deputados, 2002.

BARBI, Celso Agrícola. Formação, seleção e nomeação de juízes no Brasil, sob o ponto de vista da humanização da justiça. In: ALVIM, Arruda (Dir.). Revista de Processo, São Paulo: Revista dos Tribunais, v. 11 e 12, jul./dez. 1978.

BOBBIO, Norberto. Teoria do ordenamento jurídico. 10. ed. Brasília: UnB, 1999.

$\S 1^{\circ}$. A empresa prestadora de serviços contrata, remunera e dirige o trabalho realizado por seus trabalhadores, ou subcontrata outras empresas para realização desses serviços.

$\S 2^{\circ}$. Não se configura vínculo empregatício entre os trabalhadores, ou sócios das empresas prestadoras de serviços, qualquer que seja o seu ramo, e a empresa contratante. 
CANARIS, Claus-Wilhelm. Pensamento sistemático e conceito de sistema na ciência do direito. 4. ed. Lisboa: Fundação Calouste Gulbenkian, 2008.

CHAVES, Antonio. Tratado de direito civil: responsabilidade civil. São Paulo: Revista dos Tribunais, 1985, v. 3.

CARVALHO SANTOS, J. M. Código Civil brasileiro interpretado: direito das obrigações (arts. 1505 a 1532), Rio de Janeiro: Freitas Bastos, 1961, v. XX.

CARVALHO, Washington Rocha de et allii. Dos atos unilaterais. Dos títulos de crédito. Da responsabilidade civil. Das preferências e privilégios creditórios (arts. 854 a 965). In: ALVIM, Arruda; ALVIM, Thereza (Coords.). Comentários ao Código Civil brasileiro. Rio de Janeiro: Forense, 2013, v. VIII.

CASTANHEIRA NEVES, António. Questão-de-facto-Questão-de-direito ou o problema metodológico da juridicidade (ensaio de uma reposição crítica). Coimbra: Almedina, 1967.

CAVALIERI FILHO, Sergio. Programa de responsabilidade civil. 11. ed. São Paulo: Atlas, 2014.

FERRAZ JUNIOR, Tercio Sampaio. Conceito de sistema no direito. São Paulo: Revista dos Tribunais, 1976.

GODOY, Claudio Luiz Bueno de. Comentários ao CC art. 932. In: PELUSO, Cezar (Coord.). Código Civil comentado: doutrina e jurisprudência. 12. ed. Barueri: Manole, 2018.

GODOY, Claudio Luiz Bueno de. Introdução ao estudo do direito. 5. ed. São Paulo: Atlas, 2007.

GOMES, Orlando. Obrigações. 12. ed. Rio de Janeiro: Forense, 1999.

GOMES, Orlando. Curriculum Vitae. In: Faculdade de Direito da Universidade Federal da Bahia. Estudos jurídicos em homenagem ao Professor Orlando Gomes, Rio de Janeiro: Forense, 1979, p. IX/XII.

LAMARTINE CORRÊA, J.. Conceito da pessoa jurídica. Curitiba: [S.ed.], 1962.

LARENZ, Karl. Metodologia da ciência do Direito. 3. ed. Lisboa: Fundação Calouste Gulbenkian, 1997.

LIMA, Alvino. A responsabilidade civil pelo fato de outrem. Rio de Janeiro: Forense, 1973.

LUHMANN, Niklas. Legitimação pelo procedimento. Brasília: UnB, 1980.

MAIA, Paulo Carneiro. Responsabilidade dos preponentes pela atuação de seus prepostos. In: MAIA, Paulo Carneiro (Org.). Estudos de direito civil. Rio de Janeiro: Alba, 1962.

MARANHÃO, Délio; CARVALHO, Luiz Inácio B. Direito do trabalho. 17. ed. São Paulo: FGV, 1998.

MAXIMILIANO, Carlos. Hermenêutica e aplicação do direito. 16. ed. Rio de Janeiro: Forense, 1997.

MENEZES DIREITO, Carlos Alberto; CAVALIERI FILHO, Sergio. Comentários ao novo Código Civil: da responsabilidade civil. Das preferências e privilégios creditórios (arts. 927 a 965). In: TEIXEIRA, Sálvio de Figueiredo (Coord.). Comentários ao novo Código Civil. Rio de Janeiro: Forense, 2004, v. XIII.

MELO, Albertino Daniel de. A responsabilidade civil pelo fato de outrem nos direitos francês e brasileiro. Rio de Janeiro: Forense, 1972. 
MELO, João Ozório de. Campanhas eleitorais de juízes ficam mais politizadas nos EUA. Consultor Jurídico, 16 ago. 2017 Disponível em: https://www.conjur.com.br/2017-ago-16/campanhas-eleitoraisjuizes-ficam-politizadas-eua. Acesso em: set. 2019.

NUNES FRITZ, Karina. Comentário ao EREsp. 1.280.825/RJ: prazo prescricional de dez anos para responsabilidade contratual? Revista IBERC, Minas Gerais, v. 2, n.1, jan./abr. 2019.

NUNES FRITZ, Karina. Boa-fé objetiva na fase pré-contratual: a responsabilidade pré-contratual por ruptura das negociações. Reimpr. Curitiba: Juruá, 2012.

PINTO MARTINS, Sergio. Terceirização no Direito do Trabalho. 15. ed. São Paulo: Saraiva, 2018.

PIRES DE LIMA; ANTUNES VARELA. Código civil anotado (artigos 1.ํ a 761으. 4. ed. Coimbra: Coimbra Editora, 1987, v. I.

PONTES DE MIRANDA, Francisco Cavalcanti. Tratado de Direito Privado: Parte Especial (Direito das Obrigações. Mandato. Gestão de negócios alheios sem outorga. Mediação. Comissão. Corretagem). 3. ed. Rio de Janeiro: Borsoi, 1972, t. XLIII.

RODOVALHO, Thiago. Abuso de direito e direitos subjetivos, São Paulo: Revista dos Tribunais, 2011.

RODOVALHO, Thiago. Cláusula arbitral nos contratos de adesão: contratos de adesão de consumo contratos de adesão civis - contratos de adesão empresariais. São Paulo: Almedina, 2016.

RODOVALHO, Thiago. Obrigações e riscos. In: MIRANDA, Jorge (Dir.). O Direito. Lisboa: Almedina, 2014, v. IV.

RODOVALHO, Thiago. Princípios do direito privado e o registro de imóveis no Brasil, In: BATISTA, Alexandre Jamal (Org.). Princípios, cláusulas gerais e conceitos jurídicos indeterminados nos institutos de direito privado: homenagem ao Professor Doutor Francisco José Cahali. São Paulo: IASP, 2017.

RODOVALHO, Thiago. Das Rechtsstaatsprinzip (O princípio do estado democrático de direito) e a segurança jurídica. Revista Forense, Rio de Janeiro, v. 108, n. 415, p. 291-315. jan./jun. 2012.

RODRIGUES, Francisco Cesar Pinheiro. Juízes decidem a favor de seus "apoiadores". Consultor Jurídico, 18 set. 2009. Disponível em: https://www.conjur.com.br/2009-ago-18/juizes-eleitos-povoeua-decidem-favor-apoiadores. Acesso em: set. 2019.

ROMANO MARTINEZ, Pedro (Entrevista). Deixar o Direito do Trabalho alheio ao Direito Civil não é benéfico. Consultor Jurídico, $1^{\circ}=$ jan. 2017. Disponível em: https://www.conjur.com.br/2017-jan01/entrevista-pedro-romano-martinez-diretor-universidade-lisboa. Acesso em: set. 2019.

SADER, Emir. Consulta: juízes devem ser eleitos pelo voto popular? Carta Capital, 26 fev. 2009. Disponível em: https://www.cartamaior.com.br/?/Blog/Blog-do-Emir/Consulta-juizes-devem-ser-eleitospelo-voto-popular-/2/23992. Acesso em: set. 2019.

SERPA LOPES, Miguel Maria de. Curso de direito civil: fontes acontratuais das obrigações. Responsabilidade civil. 4. ed. Rio de Janeiro: Freitas Bastos, 1995, v. 5.

STEIN, Ernildo. Racionalidade e existência: o ambiente hermenêutico e as ciências humanas. 2. ed. ljuí: Unijuí, 2008.

TEPEDINO, Gustavo. Das várias espécies de contrato. Do Mandato. Da Comissão. Da agência e distribuição da corretagem. Do transporte (arts. 653 a 756). In: TEIXEIRA, Sálvio de Figueiredo (Coord.) Comentários ao novo Código Civil. Rio de Janeiro: Forense, 2008, v. X. 
Recebido: 04.11.2019

Aprovado: 09.11.2019

Como citar: RODOVALHO, Thiago. Responsabilidade civil e terceirização: um necessário diálogo entre direito civil e direito do trabalho. Revista IBERC, Minas Gerais, v. 2, n. 3, p. 1-15, set./dez. 2019. 